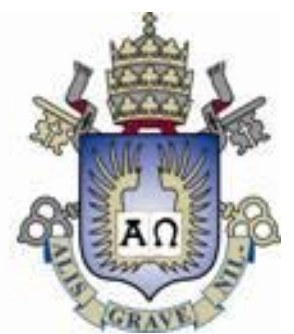

Wania Manso de Almeida

\title{
A institucionalização do ensino industrial no Estado Novo português e no Estado Novo brasileiro: aproximações e distanciamentos
}

Tese de Doutorado

Tese apresentada ao Programa de Pós-Graduação em Educação da PUC-Rio como requisito parcial para obtenção do título Doutor em Educação.

Orientadora: Ana Waleska Pollo Campos Mendonça 
Wania Manso de Almeida

A institucionalização do ensino industrial no Estado Novo português e no Estado Novo brasileiro: aproximações e distanciamentos

\begin{abstract}
Tese apresentada ao Programa de Pós-Graduação em Educação como requisito parcial para obtenção do título de Doutorado em Educação. Aprovada pela Comissão Examinadora abaixo assinada.
\end{abstract}

Prof ${ }^{\mathrm{a}}$ Ana Waleska Pollo Campos Mendonça Departamento de Educação, PUC-Rio

Prof $^{\mathrm{a}}$ Alicia Maria Catalano de Bonamino Departamento de Educação, PUC-Rio - Rio de Janeiro

Prof $^{a}$ Cynthia Paes de Carvalho Departamento de Educação, PUC-Rio

Prof ${ }^{\mathrm{a}}$ Tereza Maria Rolo Fachada Levy Cardoso CEFET Suckow da Fonseca - Rio de Janeiro

Luís Alberto Marques Alves

Faculdade de Letras - Universidade do Porto, Portugal

Prof $^{\circ}$. Paulo Fernando Carneiro de Andrade Coordenador Setorial do Centro de Teologia e Ciências Humanas PUC-Rio 
Todos os direitos reservados. É proibida a reprodução total ou parcial do trabalho sem autorização da universidade, da autora e do orientador.

\section{Wania Manso de Almeida}

Graduada em Pedagogia pela Faculdade de Filosofia de Itaperuna, Mestre em Educação pela UFES, professora, Pedagoga no Instituto Federal Fluminense, Campus 2Macaé

\section{Almeida, Wania Manso de}

A institucionalização do ensino industrial no Estado Novo português e no Estado Novo brasileiro: aproximações e distanciamentos / Wania Manso de Almeida ; orientadora: Ana Waleska Pollo Campos Mendonça. - 2010.

255 p. : il ; $30 \mathrm{~cm}$

Tese (Doutorado em Educação)-Pontifícia Universidade Católica do Rio de Janeiro, Rio de Janeiro, 2010.

Inclui bibliografia

1. Educação - Teses. 2. Ensino industrial. 3. Ensino técnico. 4. Educação comparada. 5. Reforma de ensino. I. Mendonça, Ana Waleska Pollo Campos. II. Pontifícia Universidade Católica do Rio de Janeiro. Departamento de Educação. III. Título.

CDD: 888 


\section{Agradecimentos}

À professora Dra. Ana Waleska Pollo Campos Mendonça pela firmeza de conhecimento, cordialidade e tranqüilidade com que conduziu a orientação desta tese.

Um agradecimento especial ao professor Dr. Luis Alberto Marques Alves pela orientação competente, estímulo e boa acolhida na Universidade do Porto, Portugal, durante o doutorado sanduíche, fundamentais para a realização desta pesquisa.

Ao governo do Brasil, através da CAPES, pelo apoio financeiro para realização do doutorado sanduíche.

Ao Colegiado do Centro Federal de Educação Tecnológica de Macaé por me conceder afastamento do trabalho, viabilizando a realização do Curso de Doutorado.

À minha família, Luis, Marilda, Lucia, Catarina, Regina, pelo apoio, cada um a seu tempo e com sua arte. 


\section{Resumo}

Almeida, Wania Manso; Mendonça, Ana Waleska Pollo Campos (Orientadora). A institucionalização do ensino industrial no Estado Novo português e no Estado Novo brasileiro: aproximações e distanciamentos. Rio de Janeiro, 2010, 255 p. Tese de Doutorado Departamento de Educação. Pontifícia Universidade Católica do Rio de Janeiro.

Esta tese investiga os processos de institucionalização do ensino industrial no contexto do Estado Novo português, sob o governo de Salazar (1933 - 1968) e do Estado Novo brasileiro (1937-1945), quando foram instituídas, nos dois países, reformas de ensino técnico industrial. A base documental inclui textos legais, atas de sessões parlamentares, pareceres, atas de congressos, discursos, relatórios, correspondência pessoal, artigos de revistas. Na pesquisa foi utilizada a abordagem teórico-metodológica denominada história da educação comparada na qual a procura da análise das relações entre fenômenos locais e globais toma o lugar da comparação entre as nações. A tese se estrutura em seis capítulos. O primeiro capítulo apresenta a pesquisa. O segundo e o terceiro capítulo apresentam e analisam o ensino técnico industrial em Portugal desde a gênese da proposta de educação para a cidadania na Primeira República portuguesa até a instauração do Estado Novo no início da década de 1930. A seguir, expõe aspectos do contexto político, cultural e econômico de Portugal que irão sedimentar o surgimento da reforma do ensino técnico em 1948, analisada desde a constituição da comissão de reforma de ensino até a sua institucionalização. O quarto e o quinto capítulo expõem e analisam o surgimento do sistema de ensino industrial no Brasil desde a implantação das Escolas de Aprendizes e Artífices, em 1909, até as mudanças ocorridas na década de 1930 e o processo de criação e implantação da reforma orgânica do ensino industrial promulgada em 1942. A leitura comparativa das reformas de ensino técnico industrial no Brasil e em Portugal é realizada no sexto e último capítulo onde se destacam aspectos de aproximação e distanciamento entre as duas experiências de ensino.

\section{Palavras-chave}

Ensino industrial, ensino técnico, educação comparada, reforma de ensino. 


\section{Abstract}

Almeida, Wania Manso; Mendonça, Ana Waleska Pollo Campos (Advisor). The process of institutionalization of industrial education of the Portuguese and Brazilian New State: similarities and differentiation. Rio de Janeiro, 2010, 255 p. PhD Dissertation - Departamento de Educação. Pontifícia Universidade Católica do Rio de Janeiro.

This study investigates the institutionalization of industrial education in the Portuguese New State context under Salazar's government (1933 - 1968) and the Brazilian New State (1937-1945), when the technical-industrial education reforms were institutionalized in both countries. The data-base include legal texts, parliamentary session minutes, congresses, directives, discourses, reports, private correspondence, article and magazines. We used a methodological theoretical approach called the History of Comparative Education, in which the analysis of the relation between local and global fenomena substitutes the comparison between nations. The thesis is structured around six chapters. The first chapter is on objectives, methodology and organization of the paper. The second and third chapters deal with technical-industrial education in Portugal from the beginning of the proposal of education to citizenship in the First Republic until the installation of the New State in 1933. Next, it presents aspects of political, cultural and economic aspects of Portugal, and the start and institutionalization of the technical education reform in 1948. The fourth and fifth chapters analyse the start of the industrial education system in the Brazil from the implementation of Apprentice and Craftsmen Schools in 1909 to the changes which occurred in 1930 . The chapters also deal with the creation process and implementation of the organic reform of the industrial education put forward in 1942. The comparative reading of the technical-industrial education reforms in Brazil and Portugal is done the sixth and last chapters, where aspects of similarities and differentiation between both teaching experiences are highlighted.

\section{Key-words}

Industrial education, technical education, comparative education, teaching reform. 


\section{Sumário}

1 Introdução

2 O Ensino Técnico Industrial em Portugal da República ao Estado Novo

2.1 O ensino na Primeira República portuguesa 19

2.2. O Ensino Técnico na Primeira República portuguesa 28

2.2.1. Contradições da reforma do Ensino Industrial e Comercial de 1918

2.3 Da República ao Estado Novo: gênese de um novo projeto de formação profissional

2.3.1. Linhas de força nos relatórios das reformas de 1918, 1930, 1931

2.3.2 A organização do ensino técnico nas reformas de 1918, 1930, 1931

2.3.3 A configuração curricular dos cursos industriais nas reformas de ensino de 1918, 1930 e 1931

2.3.4. Professores, mestres, alunos

3 Onsino Técnico Industrial no Estado Novo português

3.1. O Estado Novo português e a instauração de uma nova agenda política, cultural econômica

3.2. O ensino no Estado Novo Salazarista

3.3. A reforma do ensino técnico de 1948: caminhos de sedimentação de um novo modelo de formação profissional

3.3.1. A gênese da reforma do ensino técnico de 1948

3.3.2. Os princípios político-pedagógicos da reforma do ensino técnico de 1948

3.3.3. Limites, inovações, oposições na proposta de reforma do ensino técnico de 1948 
3.4.2 Os currículos dos cursos industriais 109

4 O ensino Técnico Industrial no Brasil da República Velha ao Estado Novo

4.1. Apostas iniciais da União no ensino profissional: as Escolas de Aprendizes Artífices

4.1.2. A padronização dos currículos nas Escolas de Aprendizes Artífices

122

4.2. A educação no Governo Provisório: das esperanças democráticas à modernização conservadora

4.2.1. Getúlio Vargas: novo líder para novos tempos 128

4.2.2. Um novo modelo de país: o Brasil moderno 129

4.2.3. A educação do Governo Provisório ao Estado Novo 131

4.2.4. As reformas Francisco Campos 134

4.3. O ensino industrial do Governo Provisório ao Estado Novo 138

4.4. Anísio Teixeira e a reforma do Ensino Técnico Secundário no Distrito Federal 140

4.4.1. A unificação do ensino 144

4.4.2. As Escolas Técnicas Secundárias do Distrito Federal: as casas de educação

5 O Ensino Técnico Industrial no Estado Novo Brasileiro 166

5.1. O Estado Novo brasileiro e a instauração de uma nova agenda política, econômica e cultural

5.2. O ensino no Estado Novo brasileiro

5.3. A reforma orgânica do ensino industrial de 1942: caminhos de sedimentação de um novo modelo de formação profissional no Brasil 178 5.3.1. A reforma orgânica do ensino industrial: a (im)possível conciliação de interesse 178

5.3.2. A formação dos operários da indústria na visão dos empresários: um projeto de direção moral, cultural e ideológica 
5.3.3. Capanema, entre o humanismo e a técnica - "a democracia possível"

5.3.4. O projeto de reforma orgânica do ensino industrial 199

5.4. A organização do ensino industrial na reforma de 1942

5.4.1. Modalidades e graus de ensino 202

5.4.2. A organização do ensino industrial básico 210

5.4.3. Alunos e professores 211

5.4.4 Alunos e professores 217

6 Interconexões nas reformas de ensino técnico de Portugal e do

Brasil 226

6.1. Interconexões - Educação Nova e Congressos Internacionais 227

6.1.1. A Escola Nova na institucionalização do ensino técnico industrial 227

6.1.2. Os congressos internacionais na institucionalização do ensino técnico industrial 233

6.2. Interconexões em destaque 236

6.2.1. Fragmentação das reformas do ensino industrial 236

6.2.2. Gratuidade do ensino 237

6.2.3. Da formação profissional na Escola antes do emprego à formação no local de trabalho 238

6.2.4. A aprendizagem profissional dos operários das indústrias $\quad 249$

6.2. 5. Os currículos dos cursos industriais 243

6.2.6. Educação Feminina 245

6.2.7. Os professores e mestres 246

7 Referências Bibliográficas 


\section{Lista de figuras}

Figura 1. Evolução das taxas de analfabetismo em Portugal, Espanha, Itália, Bélgica e França, entre 1875 e 1925

Figura 2. Quadro de Escolas em 1918, definido pelo Decreto $5.029 \quad 37$

Figura 3. Estrutura do Ensino conforme a Reforma de 1918

Figura 4. Plano de estudo. Curso de Marceneiro. 1930

Figura 5. Planos de Estudo. Curso de Marceneiro. 1931

Figura 6. 1931- Plano de Estudo. Curso de Pintor Cerâmico 53

Figura 7. 1931- Plano de estudo - Curso de Pintor cerâmico -

Província 53

Figura 8. Evolução percentual da taxa de analfabetismo na população maior de 7 anos. Portugal 1864-1940 76

Figura 9. Percentagem de crianças dos 7 aos 11 anos que não freqüentavam a escola. 1890 a 1955 Figura 10. Alunos adolescentes e adultos inscritos no ensino primário. 1951-1952 a 1959-1960

Figura 11. Pessoal Docente em Serviço nas Escolas do Ensino Técnico Profissional

Figura 12. Freqüência Global nas Escolas de Ensino Técnico

Profissional

Figura 13. Indicadores sobre o Ensino Secundário Técnico em 1945

e 1970

Figura 14. Estrutura do Decreto Lei no 37 029, Estatuto do ensino profissional industrial e comercial de 25/08/1948

Figura 15. Ensino Profissional Industrial e Comercial 108

Figura 16. Curso de formação industrial de marceneiro embutidor 112

Figura 17. Matrícula e Frequência nas Escolas de Aprendizes

Artífices: 1921 - 1932 
Figura 18. Matrícula no Ensino Primário e no Ensino Médio.

1920-1970

Figura 19. Expansão do Ensino Superior no Brasil. 1929-1969. 133

Figura 20. Matérias e disciplinas dos Cursos Técnicos Secundários 152

Figura 21. Seções de oficinas e ofícios dos estabelecimentos de ensino profissional

Figura 22. Organização dos cursos das Escolas Técnicas

Secundárias do Distrito Federal. 1932-1934

156

Figura 23. Escolas Técnicas Secundárias do Distrito Federal 1932-1934. Currículo dos Cursos Técnicos Industriais

Figura 24. Quadro de mestres e contra-mestres do Ensino Técnico Secundário do Distrito Federal. 1932

Figura 25. Distribuição dos professores das Escolas Técnicas

Secundárias por seção. DF. 1934.

Figura 26. Brasil - Taxas anuais de crescimento. 1920-1945

169

Figura 27. Número de sindicatos e empresas que responderam ao questionário - 1939

Figura 28. Estrutura do Dec. Lei no 4 073, lei orgânica do ensino industrial de 30/01/1942 204

Figura 29. Discriminação dos Cursos Técnicos por sessões 208

Figura 30. Articulação entre os níveis de ensino segundo as Leis orgânicas. 1942-1946

Figura 31. Sessões e cursos do ensino industrial básico 212

Figura 32. Cursos industriais básicos: distribuição de carga horária semanal por série

Figura 33. Curso de máquinas e instalações elétricas: distribuição de carga horária semanal por disciplina 214

Figura 34. Curso de didática do Ensino Industrial 219

Figura 35. Curso de Administração do ensino industrial 220

Figura 36. Dotações orçamentárias para o ensino industrial, (1910-1910) 222

Figura 37. Rede nacional de ensino industrial. Set. 1944 